\title{
CORRIGENDUM
}

\section{Why spheroids orient preferentially in near-wall turbulence - CORRIGENDUM}

\author{
Lihao Zhao and Helge I. Andersson \\ doi:10.1017/jfm.2016.619, Published online by Cambridge University Press, \\ 18 October 2016
}

The reference Capone \& Romano (2015) was published with an incorrect article title. The correct reference is as follows:

Capone, A. \& Romano, G. P. 2015 Interactions between fluid and fibers in a turbulent backward-facing step flow. Phys. Fluids 27, 053303.

The authors apologise for this error.

\section{REFERENCE}

CAPone, A. \& Romano, G. P. 2015 Interactions between fluid and fibers in a turbulent backwardfacing step flow. Phys. Fluids 27, 053303.

ZHAO, L. \& ANDERSSON, H. I. 2016 Why spheroids orient preferentially in near-wall turbulence. J. Fluid Mech. 807, 221-234. 